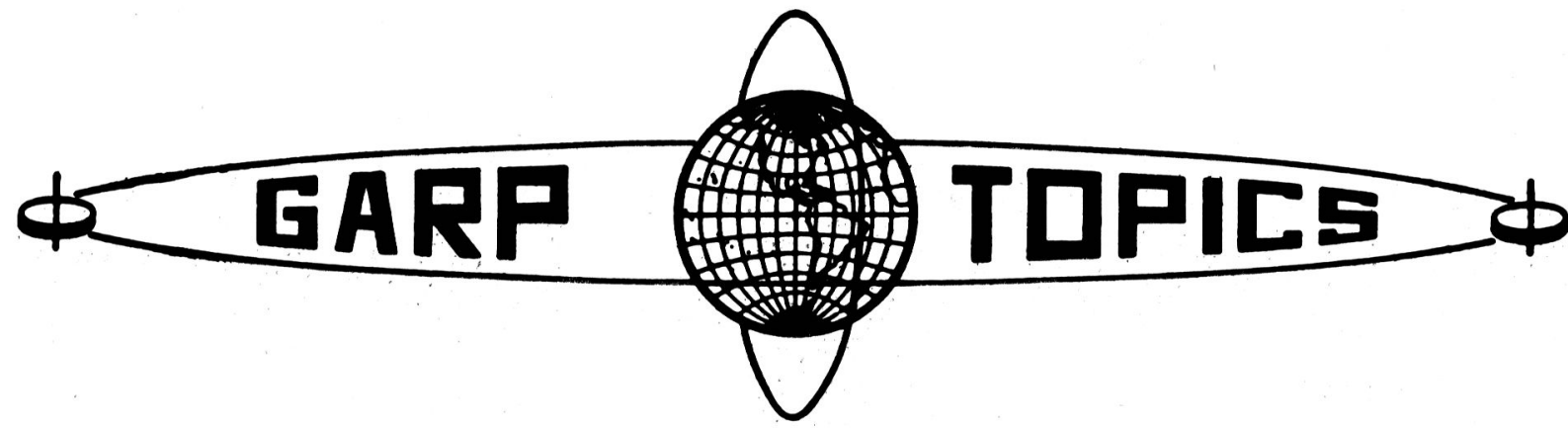

No. 68

September 1981

An occasional series reporting on U.S. and international GARP scientific, technical, and planning activities, developments, and programs, presented as a public service to the meteorological community by the American Meteorological Society through arrangements with the U.S. Committee on the Global Atmospheric Research Program of the National Academy of Sciences-National Research Council. Opinions expressed in "GARP Topics" do not necessarily reflect the point of view of the U.S. Committee.

\title{
Nimbus-6 Temperature Soundings Obtained Using Interactive Video-Graphics Computer Techniques
}

\author{
Byron A. Paulson ${ }^{1}$ and Lyle H. Horn \\ Department of Meteorology, University of Wisconsin, Madison, Wis. 53706
}

\begin{abstract}
In an attempt to improve the quality of Nimbus- 6 soundings, the Man-computer Interactive Data Access System (McIDAS) at the University of Wisconsin is used to manually edit individual (scan spot) High-resolution Infrared Sounder (HIRS) soundings. Unlike the Nimbus-6 Data System Test (DST) soundings that are derived from averages of up to 84 spot radiance measurements and the TIROS-N and NOAA- 6 operational soundings that can involve averages of up to 63 spot measurements, the HIRS soundings used in this study were derived from single spot radiances or averages of five single spot soundings. Also, unlike the DST soundings, the HIRS McIDAS retrievals used contemporary surface (instrument shelter) temperatures as a pseudoinfrared window channel to aid in cloud filtering. These McIDAS-generated soundings were used to analyze 1 ) level temperature fields at 850,500 , and $300 \mathrm{mb} ; 2$ ) the $850-300 \mathrm{mb}$ thickness field; and 3) the $500 \mathrm{mb}$ height field over eastern Europe for a 20 August 1975 case. The excellent radiosonde network in this area is used for verification purposes.

While the individual spot soundings offer little improvement over the DST data, the averages of five of these soundings provide analyses that are distinctly superior to the operational DST soundings. Although improvement is noted in the root mean square and bias
\end{abstract}

\footnotetext{
${ }^{1}$ Present affiliation: National Weather Service, Minneapolis, Minn. 55450.
}

0003-0007/81/091308-11\$06.75

(c) 1981 American Meteorological Society scores, the largest improvements are found in the $S_{1}$ score, which is a measure of gradient comparison. The radiosonde verification data are partitioned into subsets and in some tests are combined with the HIRS soundings. Other tests involve comparisons in which the radiosonde data consist of only mandatory-level data. The various tests indicate that the edited HIRS soundings averaged in small groups are comparable to mandatory-level radiosonde data in constructing $500 \mathrm{mb}$ height analyses.

\section{Introduction}

Vertical temperature profiles retrieved from satellite-measured radiances have been an important component of the GARP (Global Atmospheric Research Program) observational system. Although satellite soundings have the potential for providing the global data needed for operational numerical prediction models, their effectiveness has been inconclusive. Impact studies conducted by the National Meteorological Center (NMC) have indicated that the inclusion of satellite soundings into the NMC data base did not improve the numerical model forecasts (Tracton et al., 1980). On the other hand, Ghil et al. (1979) and Kelly et al. (1978) have reported some forecast improvement when Nimbus-6 satellite sounding data were included as input for the National Aeronautics and Space Administration's (NASA) 
and Australian Numerical Research Centre's prediction models, respectively. While the ultimate test of the effectiveness of satellite soundings will be their ability to improve numerical weather predictions, it is difficult to evaluate these new data when they are combined with radiosonde and other meteorological data in complex numerical models.

Because of the difficulty of assessing the quality of satellite soundings, it is important that they be evaluated in studies that directly reveal their strengths and limitations. For example, Phillips et al. (1979) recently used TIROS-N satellite soundings with colocated radiosonde observations to study some of the peculiarities of the satellite soundings, particularly their error characteristics under varying degrees of cloudiness. Another approach is to compare descriptions of synoptic features obtained from satellite sounding data only with those obtained from radiosonde data only. The primary focus of these studies is on comparisons of gradients obtained from the two data sets. Horn et al. (1976) found that Nimbus- 5 soundings used alone were capable of describing the intense thermal gradient beneath an upper-tropospheric jet streak, while Petersen and Horn (1977) successfully used Nimbus-6 soundings to track a $500 \mathrm{mb}$ low. In both studies success was in part attributed to the screening of the satellite soundings, thus eliminating obviously poor data. Despite "clear column" techniques developed by the National Earth Satellite Service (NESS) to reduce the effects of clouds, most poor soundings result from cloud contamination of the infrared radiances.

The satellite soundings screened in the studies just noted were part of the Data System Test (DST) data base produced by NESS as a forerunner to the current TIROS-N and NOAA-6 operation. Each DST sounding uses an objectively derived average of many individual radiance measurements, theoretically as many as 84 . Because improved results were obtained by screening these averaged data, it was decided to determine if even greater improvement might be achieved by manually screening individual data before averaging, rather than using a purely objective scheme.

This report focuses on the improvements achieved in the Nimbus-6 soundings when manually edited spot soundings are used either individually or in small groups (up to five spots) to obtain an "operational" sounding. This objective is in accordance with the GARP "Special Effort" recommendation that attempts be made to achieve the highest possible horizontal resolution in the sounding data (Greaves et al., 1979). It should be added that the NESS Mesoscale Applications Group at the University of Wisconsin-Madison is employing a somewhat similar procedure, constructing TIROS-N and NOAA-6 operational soundings from the averages of up to nine spots.

The edited Nimbus- 6 soundings obtained in this study are tested by using them to construct 850,500 , and $300 \mathrm{mb}$-level temperature fields, an $850-300 \mathrm{mb}$ thickness field, and 500 $\mathrm{mb}$ height fields, which are compared with fields obtained from radiosonde data. Nimbus- 6 data gathered over central and eastern Europe on 20 August 1975 are used. This area was chosen because its dense radiosonde network provides an excellent verification data set. The satellite passage occurred near radiosonde time and during a period when all channels of the Nimbus- 6 infrared sounder were operational. Since the infrared sounder aboard Nimbus- 6 and the process-

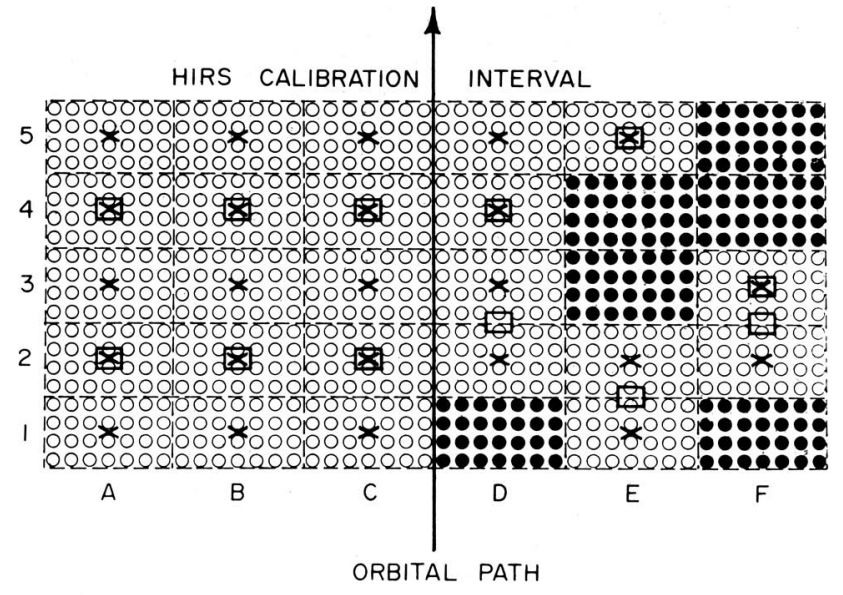

FIG. 1. A schematic of HIRS data averaging. Circles represent individual HIRS fields of view. In this example, solid circles indicate fields of view not used because of cloud contamination. Dashed lines outline HIRS $4 \times 7$ blocks. The $4 \times 7$ soundings are located by Xs. The DST soundings, based on overlapping averaging of $4 \times 7$ blocks, are indicated by squares ( $\square$ ). At A-4. the DST sounding consists of the averages of the A-5,-4, and -3 blocks, while the DST sounding at E- 5 consists of only one $4 \times 7$ block because of cloud contamination in adjacent regions.

ing procedures are essentially the same as those of TIROS-N and NOAA-6, the results achieved here very likely also apply to the current polar-orbiting sounders. Before describing the editing method and its results, it is important to review briefly the Nimbus- 6 instrument and retrieval procedures.

\section{Instruments and retrieval procedures}

Nimbus-6, launched 12 June 1975 into a nearly sun-synchronous orbit of $1100 \mathrm{~km}$, carried two sounding instruments: the High-resolution Infrared Sounder (HIRS) and the Scanning Microwave Spectrometer (SCAMS). HIRS provides radiance measurements in 17 spectral bands; seven in the $15 \mu \mathrm{m}$ region, five in the $4.3 \mu \mathrm{m}$ region, and the remainder in window regions and water vapor bands. The HIRS instrument scans perpendicular to its orbital path, $36.9^{\circ}$ to the right and left, which on the earth's surface amounts to about $825 \mathrm{~km}$ on either side of the nadir path. At the subsatellite point the ground resolution of an individual HIRS field of view is approximately $30 \mathrm{~km}$.

The SCAMS instrument has five channels that measure microwave radiances; three in the spectral band near $0.5 \mathrm{~cm}$ for temperature sounding and two near $0.2 \mathrm{~cm}$ for moisture sounding. The instrument scans $43.2^{\circ}$ to the right and left of its orbital path in $7.2^{\circ}$ steps. Since it measures less intense radiation than HIRS, it requires a larger field of view, approximately $145 \mathrm{~km}$ at nadir. However, the SCAMS has an advantage in that it is not significantly affected by nonprecipitating clouds. See the Nimbus-6 User's Guide (NASA, 1975) for more complete descriptions of the instruments.

In order to appreciate the editing procedure used in this study, it is first necessary to understand the manner in which 


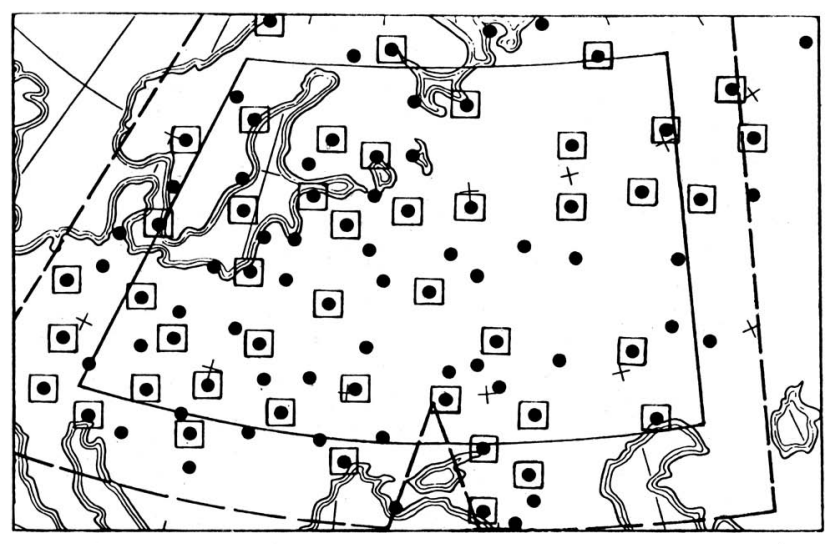

FIG. 2. Area of study. Dashed lines indicate area in which retrievals were made from two orbits of Nimbus-6. Solid interior lines denote analysis area. Solid circles indicate radiosonde station locations. Stations with boxes around circles are locations of the RR1 network. Remaining circles represent the RR2 network. See text.

the Nimbus-6 soundings were processed for DST. In one scan (left and right of its orbit), HIRS measures radiances in 42 fields of view (see Fig. 1). After completing 20 such scans, HIRS enters a calibration mode, causing a short gap in transmission. These 840 fields of view $(42 \times 20)$, could, under ideal conditions, produce 840 individual soundings roughly $30 \mathrm{~km}$ apart. However, factors such as clouds, varying surface emissivities, pronounced surface elevation changes, and instrument noise cause some of the radiances to be unsuitable for temperature retrievals.

Because such a dense array of individual soundings is unmanageable and impractical for most purposes, NESS divided each 840 member array into 30 subsets of $4 \times 7$ fields of view (four along the orbital path by seven across the path). Within a $4 \times 7$ block, each individual HIRS measurement is checked for consistency (and possibly discarded) using SCAMS measurements interpolated to the HIRS fields of view. (Recall the SCAMS radiances are not degraded by nonprecipitating clouds.) Acceptable radiances are then combined in a manner described by Smith and Woolf (1976). Their method, designed to minimize the effect of cloud contamination, yields a set of clear column (cloud-free) infrared radiances representative of the $4 \times 7$ block. In the example shown in Fig. 1, the $4 \times 7$ blocks marked with $X$ s have cloud-free infrared radiances suitable for retrieving vertical temperature profiles. These cloud-free infrared radiances are supplemented with SCAMS radiances interpolated to the cloud-free radiance locations. NESS furnished a sounding at each of these locations in the basic DST data set.

During the DST processing of the satellite retrievals, NMC found that the number of $4 \times 7$ soundings (up to 30 between calibration intervals) was too large to handle in operational work. A maximum of 12 soundings was chosen as manageable, which resulted in a further averaging of the $4 \times 7$ arrays. The center location of the final averages is shown by the squares of Fig. 1. These averaged radiances and the eigenvector approach described by Smith and Woolf (1976) were used to retrieve the so-called DST soundings. Because there are only five $4 \times 7$ radiance blocks along the orbital path between calibration intervals, overlapping averaging was re- quired. For example, on the left side of Fig. 1, blocks 1, 2, and 3 were averaged to yield a DST sounding (square) centered in block 2 . Likewise blocks 3,4 , and 5 were averaged to obtain the sounding centered in 4 . When some of the $4 \times 7$ blocks were unavailable, the averaging may have involved only 2 blocks, and in some cases only one block (Columns $\mathrm{E}$ and $\mathrm{F}$ in Fig. 1).

It is well recognized that analyses based on DST soundings are usually smoother (e.g., they contain weaker gradients) than those obtained from radiosonde data. While a major part of this smoothing probably reflects the lack of vertical resolution in satellite soundings, the horizontal averaging of many individual spot soundings used in obtaining the DST soundings can contribute to some loss of horizontal resolution, especially of smaller-scale features. ${ }^{2}$

\section{Alternate selection procedures}

A major goal of this study is to determine whether the quality of satellite soundings can be improved through manual selection and limited averaging of individual soundings (fields of view). Individual soundings were selected using the University of Wisconsin's video-graphics Man-computer Interactive Data Access System (McIDAS). The manually selected soundings obtained in this study were based on the same radiance measurements used in the DST soundings; however, the temperature profile retrievals made using McIDAS were based on a simple regression approach rather than the eigenvector method employed in obtaining DST soundings (Smith et al., 1979). The regression coefficients were calculated from the radiosonde and radiance data collected over Europe during the entire DST-6 period of 18 August-4 September 1975, which includes the 20 August case examined here. The McIDAS retrieval algorithm, unlike the DST retrieval algo-

\footnotetext{
${ }^{2}$ Phillips (personal communication, 1981) has suggested that the effect of the DST-type averaging on the loss of variance should be estimated using analytical equations. Assume an original temperature distribution $(T)$,
}

$$
T=A \cos (2 \pi x / L),
$$

where $A$ is amplitude, $x$ is the distance coordinate, and $L$ is wavelength. A smoothed function of $T$, which will be denoted as $T_{s}$, obtained from employing soundings averaged over an incremental distance $\Delta$, is given by

$$
T_{s}=\frac{1}{\Delta} \int_{x-\Delta / 2}^{x+\Delta / 2} T d x=\frac{\sin \epsilon}{\epsilon} T,
$$

where $\epsilon=\pi \Delta / L$.

Considering the DST averaging (including overlapping), calibration gaps, etc., the DST soundings are about $300 \mathrm{~km}$ apart in regions of clear skies. For $\Delta=300 \mathrm{~km}$ and $L=3000 \mathrm{~km}$,

$$
T_{s}=0.984 T
$$

which represents a very small loss of variance. However, for $\Delta=300$ $\mathrm{km}$ and $L=1000 \mathrm{~km}$,

$$
T_{s}=0.858 T,
$$

which, although not excessive, does indicate an appreciable loss of variance in this ideal analytical field. 
rithm, employed contemporary surface (instrument shelter) temperatures. (It should be noted that DST also used surface temperatures, but they were $24 \mathrm{~h}$ old.) In this study the contemporary surface temperatures were treated as a pseudoinfrared window channel during the McIDAS retrieval procedure and thus aided in filtering cloud contamination. The effect of this pseudochannel should provide improved soundings in the lowest layers (i.e., below $850 \mathrm{mb}$ ). However, as will be noted later in the paper, the existence of strong nocturnal temperature inversions over much of the study area may have partially offset the positive influence of this pseudosurface channel.

The McIDAS retrievals were made from two consecutive orbits over eastern and central Europe. The westernmost orbit brought the satellite over the region at about 2330 GMT on 20 August 1975; the adjacent orbit to the east occurred about 107 min earlier. Figure 2 (straight dashed lines) shows the area encompassed by the two orbits. Because of the relatively high latitude, data were lacking for only a small wedge-shaped area between orbits (just north of the Black Sea). Soundings from both orbits were analyzed together, neglecting the time difference. In comparing satellite soundings with the 0000 GMT radiosonde data, the time differences of an hour or two were neglected. This is a fair approximation, since about $45 \mathrm{~min}$ are required for a typical radiosonde ascent to $100 \mathrm{mb}$.

As a first step in obtaining HIRS temperature retrievals, a radiance field having the appearance of a mosaic is displayed on the McIDAS video screen. Normally the radiance field of a channel with its peak energy contribution near the surface is displayed first. Those $30 \mathrm{~km}$ HIRS fields of view (pixels) of the mosaic that are darker (greater brightness temperature) than their surroundings are generally cloud-free and good candidates for temperature retrievals. Because of the relatively small size of these fields of view, the operator can obtain soundings through breaks in a mostly overcast region. If this is not possible, the retrieval algorithm will employ a partly cloudy N-star technique (Smith, 1968) to derive a clear column radiance from two adjacent fields of view.

The McIDAS operator selects a pixel for which a temperature profile is desired. An algorithm interpolates a SCAMS measurement to the HIRS field of view, and the following data are displayed on the screen: 1) the HIRS-retrieved temperature at each mandatory level $(1000,850,700,500$, $400,300,250,200,150$, and $100 \mathrm{mb}$ ); 2) the temperature difference between the HIRS- and SCAMS-derived temperature at each mandatory level to $300 \mathrm{mb}$; and 3 ) the vertically summed rms (root mean square) temperature difference between HIRS and SCAMS over the mandatory levels to 300 $\mathrm{mb}$. The HIRS-SCAMS differences are used as the first step in the editing process.

McIDAS also is programmed to analyze the fields of retrieved temperature at the mandatory levels or the fields of brightness temperature for various radiance channels. Thus the operator can quickly select, examine, analyze, and edit retrievals.

To construct fields of retrieved temperature, soundings generally are attempted in obviously clear areas first (i.e., high brightness temperatures). Then the operator attempts retrievals in areas of partial cloud cover. After acquiring a sufficient number of temperature retrievals, McIDAS can be used to display the isotherm analysis to aid in eliminating inconsistent retrievals. The $500 \mathrm{mb}$ level usually is used in this editing, since it is above much of the low cloudiness and yet below the tropopause. However, a small amount of editing is also done at 850 and $300 \mathrm{mb}$. Once the operator is satisfied with the consistency of the analysis displayed on McIDAS, the soundings on which the analysis is based are retained as the data set. At no time during the selection and editing process are radiosonde data or surface temperatures used.

\section{Data sets}

Several sets of HIRS soundings were retrieved using the selection methods described in the previous section, but only two are examined in this paper. These soundings were "dry"; i.e., moisture data were not included. In addition to the two HIRS data sets, results obtained from DST and a set of microwave (SCAMS) soundings are included. Use of the DST set provides some insight into the data quality used in the numerical model impact studies mentioned in the introduction. The SCAMS soundings are included since they were used as an aid in editing the individual HIRS soundings, and because they are based on radiances not affected by nonprecipitating clouds. Verification was accomplished using a network of 96 radiosonde stations in the area of study. As will be discussed later, the radiosonde data set was modified to provide additional insight into the characteristics and quality of the satellite data. The various data sets, both satellite and radiosonde verification, are described in this section.

\section{a. DST soundings}

The manner in which the 76 DST soundings within the area of study were retrieved by NESS was described in detail in Section 2. As noted previously, the DST sounding retrievals were obtained using the eigenvector procedure, while the HIRS soundings of this study are based on regression retrievals. Thus, comparisons between the HIRS data sets and the original DST soundings are not entirely unequivocal.

\section{b. Manual $(M A N)$ retrievals}

The manual editing procedure yielded a total of 335 HIRS soundings, each based on a single field of view. The McIDAS operator (Paulson) attempted these retrievals in cloud-free regions. Because of the small field of view $(30 \mathrm{~km})$, some of these soundings (henceforth called the MAN set) were accomplished in breaks in generally cloudy regions also. The 335 MAN soundings were distributed rather uniformly across the study area.

\section{c. Group Co-located (GCL) soundings}

Next, a set of HIRS soundings located near radiosonde stations was produced. It was anticipated that these nearly colocated soundings would facilitate satellite-radiosonde comparisons. Initially, between 5 and 15 retrievals were made within about $70 \mathrm{~km}$ of each radiosonde station. These soundings were edited on McIDAS until only one representative 


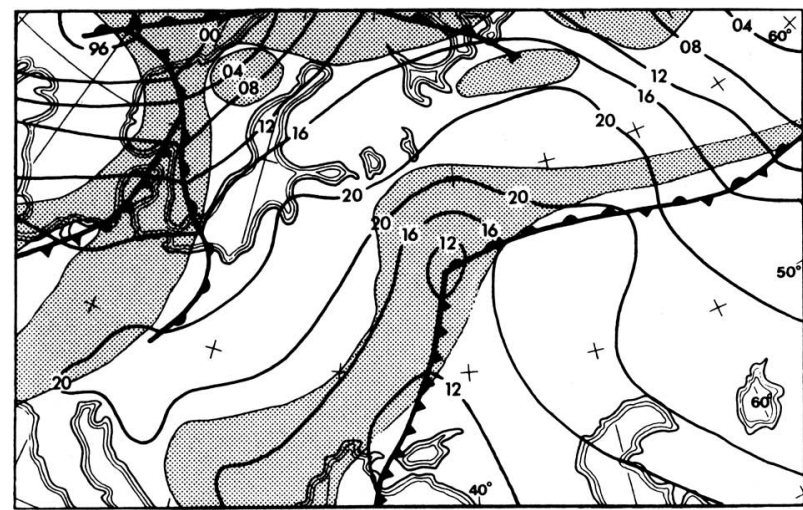

FIG. 3. Surface analysis for 0000 GMT on 21 August 1975. Stippling indicates principal areas of cloudiness.

sounding remained. (It should be emphasized again that radiosonde data were not used in the editing.) These single soundings (93 in number) were essentially co-located with radiosonde stations. Analyses based on these retrievals showed some improvement over those based on the 335 MAN retrievals. The lack of truly significant improvement appeared to be due to noise present, even after editing, in data sets based on single fields of view. Consequently, about five soundings within a $70 \mathrm{~km}$ radius of each radiosonde station were retained. A Cressman-type weighting procedure was used to interpolate these retrievals to the radiosonde station location, thus providing a single weighted sounding. (The University of Wisconsin's UNIVAC 1110 rather than McIDAS was used in the interpolation.) In the case of three of the 96 radiosonde station locations extensive cloudiness was present, so no HIRS retrievals were achieved. The 93 soundings will be called the Group Co-located (GCL) set.

\section{d. Microwave retrievals $(M W R)$}

Since part of the editing procedure used in the HIRS retrievals involves comparisons with the SCAMS retrievals, it was decided to examine the results that could have been achieved using only microwave data. This data set will be referred to as the MWR set. The microwave temperatures examined here were SCAMS retrievals interpolated to HIRS MAN sounding locations. Thus, temperatures from more than one SCAMS retrieval were often incorporated into a MWR sounding. A total of 335 such microwave soundings were generated, one for each MAN location.

\section{e. Radiosonde data sets (CRB, RR1, RR2)}

A total of 96 radiosonde stations were located within the region of study (Fig. 2). The 0000 GMT 21 August 1975 observations at those stations were used as a verification standard with which to compare the satellite data sets. While it is well recognized that radiosonde observations are not error-free, they nevertheless provide the best verification available. This set of radiosonde observations, which includes both mandatory- and significant-level data, will be referred to as the Complete RAOB (CRB) set.

To examine the effect of the density of the data network on the results and to conduct experiments in which the satellite and radiosonde data are mixed, a subset consisting of onehalf (48) of the radiosonde stations was selected. To make this subset more comparable to satellite data, only dry, mandatory-level radiosonde data were used. This set, referred to as the Reduced Radiosonde One (RR1) set, was obtained by asking a student unfamiliar with the research to select onehalf of the radiosonde stations in such a way as to ensure relatively uniform spacing (see Fig. 2). The remaining 48 radiosonde stations, not as uniformly spaced, will be called the Reduced Radiosonde Two (RR2) set. The RR2 set consisted of only dry, mandatory-level data also.

\section{f. Combined radiosonde-satellite data sets (RS1, RS2)}

In a final experiment, radiosonde data from the 48 radiosonde stations of the RR1 set were combined with GCL satellite data at the missing 48 radiosonde stations (i.e., the RR2 locations) to form a combined radiosonde-satellite data set. This combined set will be called the RS1 set. A similar set obtained by combining radiosonde data from the RR2 set with GCL satellite data at missing radiosonde locations (i.e., at the 48 RR1 locations), will be referred to as the RS2 set.

\section{Analysis procedures and experiment design}

The effectiveness of the McIDAS editing procedure was tested by comparing analyses based on the various satellite data sets with those obtained using only radiosonde data. Comparisons were done for: 1 ) the temperature fields at 850 ,

TABLE 1. Level temperature $\left({ }^{\circ} \mathrm{C}\right)$ comparisons.

\begin{tabular}{|c|c|c|c|c|c|c|c|c|c|}
\hline \multirow[b]{2}{*}{ Data } & \multirow{2}{*}{\multicolumn{2}{|c|}{$\begin{array}{c}850 \mathrm{mb} \\
\text { Bias }\end{array}$}} & \multirow[b]{2}{*}{$S_{1}$} & \multicolumn{3}{|c|}{$500 \mathrm{mb}$} & \multicolumn{3}{|c|}{$300 \mathrm{mb}$} \\
\hline & & & & RMS & Bias & $S_{1}$ & RMS & Bias & $S_{1}$ \\
\hline CRB & \multicolumn{9}{|c|}{ Verification data set } \\
\hline DST & $1.68^{\circ} \mathrm{C}$ & $0.46^{\circ} \mathrm{C}$ & 47.99 & $1.31^{\circ} \mathrm{C}$ & $0.41^{\circ} \mathrm{C}$ & 45.84 & $1.86^{\circ} \mathrm{C}$ & $-1.12^{\circ} \mathrm{C}$ & 50.73 \\
\hline MWR & 1.92 & -1.05 & 47.14 & 1.25 & -0.12 & 43.75 & 1.60 & -0.40 & 50.08 \\
\hline MAN & 1.83 & -1.09 & 44.92 & 1.41 & 0.29 & 44.70 & 1.08 & 0.21 & 44.05 \\
\hline GCL & 1.49 & -0.77 & 39.21 & 1.11 & 0.33 & 35.94 & 0.97 & 0.30 & 40.84 \\
\hline RR1 & 0.93 & .09 & 34.89 & 0.65 & 0.21 & 32.00 & 0.73 & 0.07 & 38.57 \\
\hline RS1 & 0.88 & -.36 & 27.55 & 0.57 & 0.22 & 23.07 & 0.61 & 0.11 & 29.66 \\
\hline RR2 & 1.95 & 0.40 & 46.12 & 1.03 & -0.17 & 40.24 & 1.05 & 0.01 & 44.27 \\
\hline RS2 & 0.91 & -0.45 & 26.50 & 0.84 & 0.14 & 29.42 & 0.70 & 0.20 & 27.42 \\
\hline
\end{tabular}



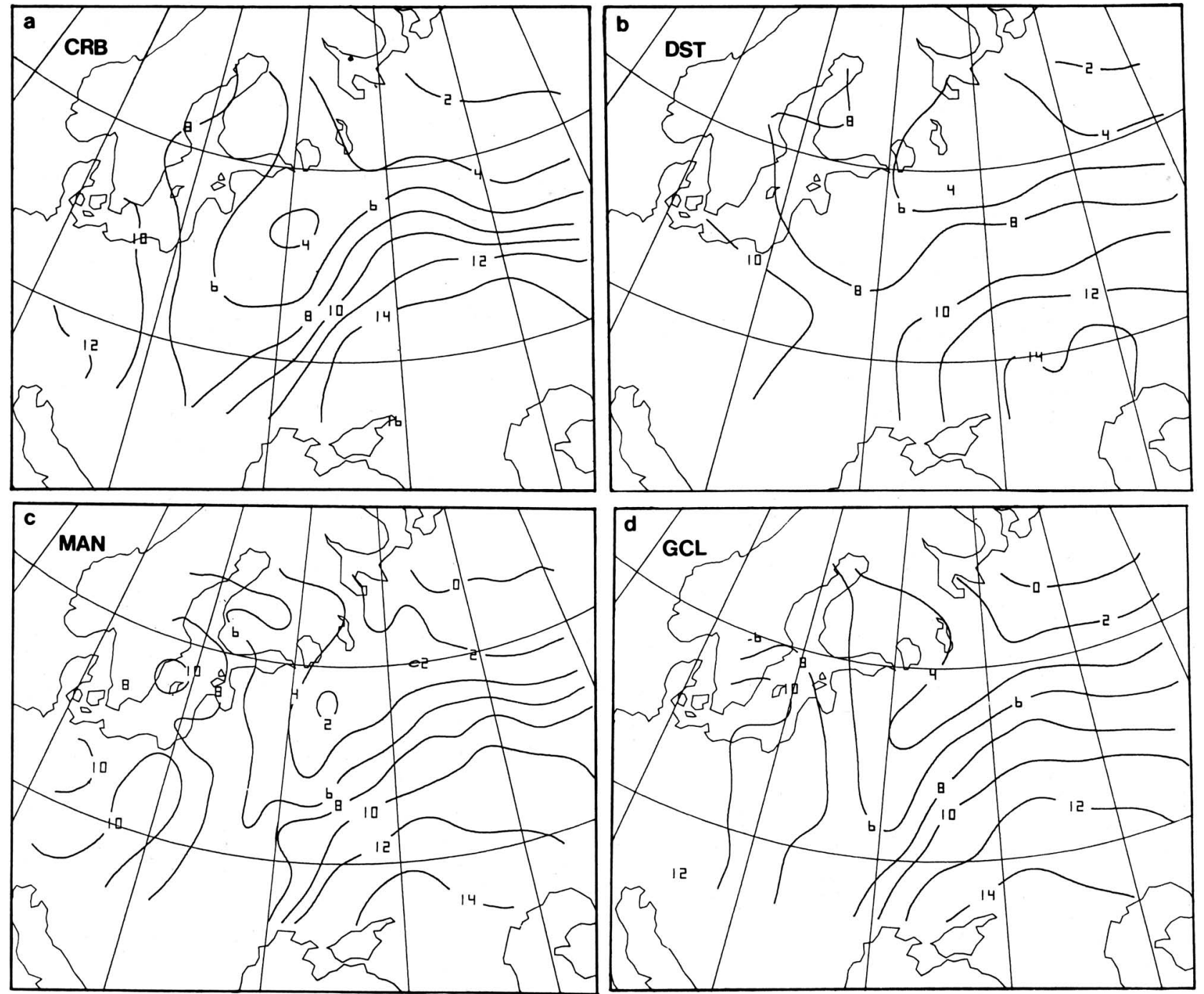

FIG. 4. Temperature analyses at $850 \mathrm{mb}$ at about 0000 GMT on 21 August 1975: a) CRB data, b) DST data, c) McIDAS MAN HIRS data, d) GCL HIRS data.

500 , and $300 \mathrm{mb} ; 2$ ) the $850-300 \mathrm{mb}$ thickness field; and 3 ) the $500 \mathrm{mb}$ height field. Each satellite data set and the reduced radiosonde networks were verified against CRB.

Analyses were done on a $1^{\circ}$ latitude-longitude grid. Both satellite and radiosonde observations were interpolated to this grid using Cressman-type weights on the five observations nearest each grid point (Whittaker, 1976). To lessen boundary problems arising from these interpolations, the analysis grid was made a subset of the larger area from which satellite soundings were retrieved (see Fig. 2).

Verification was done using the grid point results to calculate the bias, rms, and $S_{1}$ skill score. The $S_{1}$ score, a measure of the difference between gradients, is commonly used to verify forecast gradients against observed gradients. The $S_{1}$ score can range from 0 (perfect agreement) to 100 . A score of 40 in a $24 \mathrm{~h} 500 \mathrm{mb}$ forecast is considered fair and a score of 20 is very good. In this study, gradients were calculated using a $2^{\circ}$ latitude-longitude spacing (i.e., every other grid point). Because of the great importance of gradients in most meteor- ological problems, the $S_{1}$ scores are given special significance.

\section{Results}

The discussion of the results achieved through the editing procedures will be organized around the three parameters noted earlier: temperature fields at 850,500 , and $300 \mathrm{mb}$; the thickness field of the 850-300 mb layer; and several derived $500 \mathrm{mb}$ height fields. Representative maps of the $850 \mathrm{mb}$ temperature and $500 \mathrm{mb}$ height fields, and a complete set of tables showing the bias, $r m s$ differences, and $S_{1}$ scores for all comparisons will be presented.

Before examining the verification scores, a brief review of the general synoptic situation over central and eastern Europe at 0000 GMT on 21 August 1975 is in order. The surface synoptic pattern (Fig. 3) shows a frontal cyclone centered over the U.S.S.R. near $55^{\circ} \mathrm{N}, 40^{\circ} \mathrm{E}$. A second cyclone is 

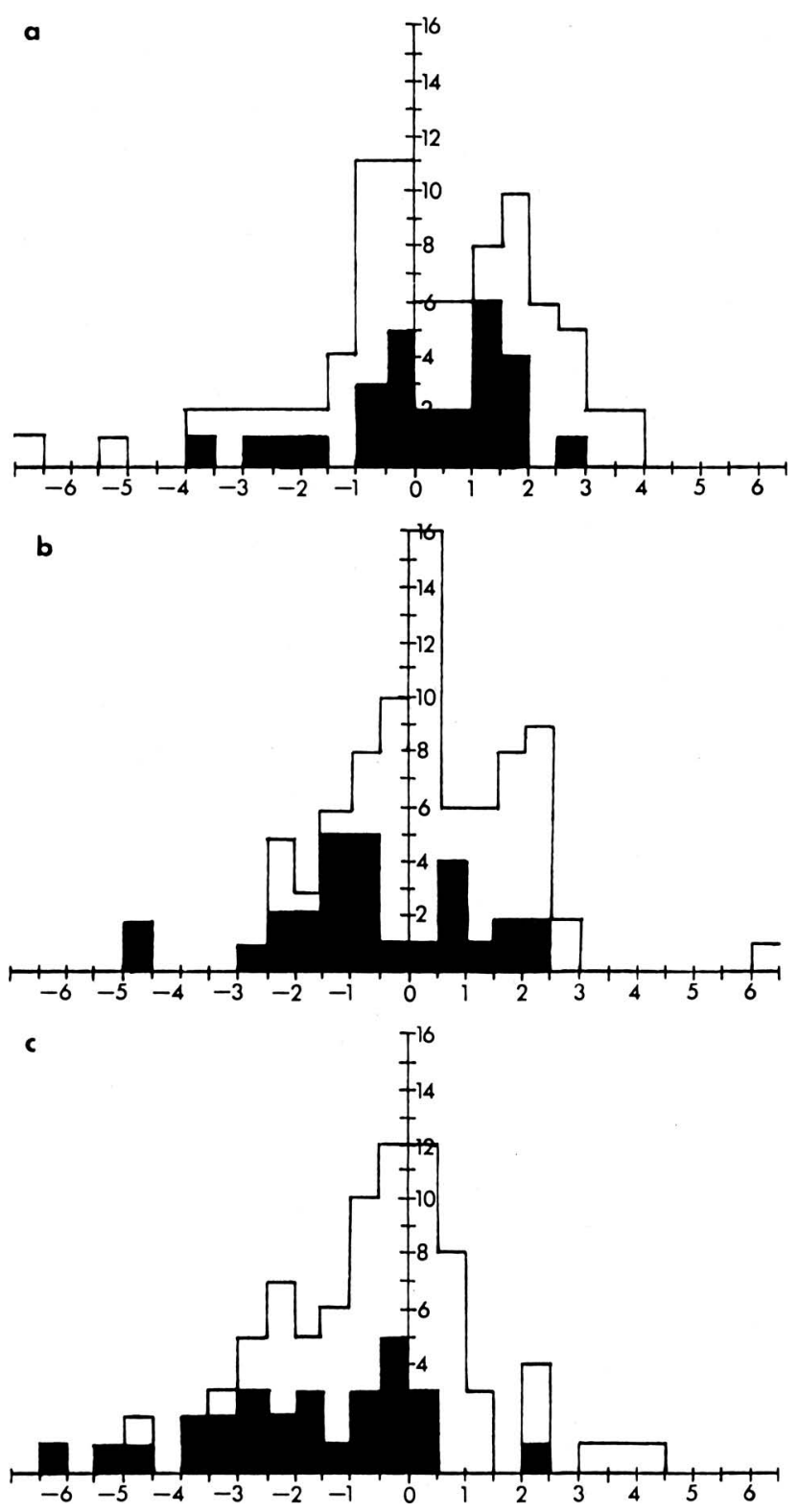

FIG. 5. Histograms showing frequency of GCL and CRB temperature differences at radiosonde station locations for a) 300 $\mathrm{mb}$, b) $500 \mathrm{mb}$, and c) $850 \mathrm{mb}$. Solid portions of bars indicate that the sounding was made in a relatively cloud area. Negative values indicate that the HIRS GCL sounding temperature was less than the radiosonde $(C R B)$ value.

centered west of Norway, with its frontal system extending southeastward into Europe. The major areas of cloudiness, shown by stippling in Fig. 3, are associated with the frontal zones. Visible and infrared images made from the NOAA-4 satellite aided in outlining these clouds. Of course, the McIDAS display of the infrared radiances of the HIRS channels, particularly those that peak at lower elevations, also reveals the presence of clouds. The $500 \mathrm{mb}$ pattern for 0000 GMT can be seen in Fig. 6a. Its major feature consists of a trough extending southward from Lake Ladoga into the Balkans. A ridge extends north-northeastward from the Alps to the Baltic Sea, with a second trough (not shown) west of Norway. All of these late summer features are rather weak, with the strongest $500 \mathrm{mb}$ winds reaching only $25 \mathrm{~m} \mathrm{~s}^{-1}$.

\section{a. Level temperature verifications}

Of all the parameters examined in this study, the level temperature retrievals probably provide the severest test for satellite data. Because of the relatively poor vertical resolution of satellite soundings, layer mean temperatures of thicknesses usually produce results closer to radiosonde data than do temperatures at a specified level. Table 1 summarizes the various data sets and verification parameters for the level temperatures at 850,500 , and $300 \mathrm{mb}$. In general, the DST and MWR soundings produced similar results when compared with the CRB data set. The MAN set has $S_{1}$ scores that are a few points better than either the DST or MWR set, although the rms differences for the MAN set show no improvement. However, the GCL HIRS soundings show marked improvement over the DST and MWR sets in both the rms and $S_{1}$ comparisons, with the $S_{1}$ scores showing about a 10 point improvement.

Figure 4 displays the objective analyses of the $850 \mathrm{mb}$ temperature field achieved from the CRB, DST, MAN, and GCL data sets. These analyses are qualitatively consistent with the scores achieved by the various satellite data sets. For example, the DST analysis lacks the gradients of the CRB set, as the $S_{1}$ score suggests. This has been a common feature in DST-radiosonde comparisons. On the other hand, the MAN set captures more of the gradients, but provides a somewhat noisy isotherm pattern (high $\mathrm{rms}$ ). This very likely results from the large number (335) of soundings used and the lack of averaging in this set. The GCL set that consists of averages of five single spot soundings provides a considerably improved field. The major gradients are described and the field is not noisy.

The improvement obtained using the GCL set over the MAN set can be attributed in part to the use of co-located (radiosonde/GCL) data in the GCL verification, but not in the MAN verification. However, as noted, single soundings chosen to be co-located with radiosonde stations (see Section $4 c)$ produced only a modest improvement over the MAN set. Consequently, we conclude that, while the use of co-located data sets in verification accounted for part of the superior performance of the GCL set over the MAN set, a major portion of the improvement results from the reduction of noise achieved by averaging five individual soundings.

A comparison of RR1 and RR2 with CRB in Table 1 provides some insight into the influence of the density of the data network. Reducing the number of radiosonde stations by one-half yields gradient information ( $S_{1}$ score) somewhat better than the GCL set when the reduced radiosonde network consists of evenly spaced stations (RR1) and considerably worse when the radiosonde stations are not spaced evenly (RR2). However, replacing the missing radiosonde stations with HIRS GCL soundings produces a very marked improvement in gradient information (i.e., $S_{1}$ scores) for the RS1 and RS2 sets. The addition of the satellite data to form the RS2 set produces a particularly impressive $S_{1}$ improvement with a comparable improvement in the rms score.

The bias scores achieved by the various satellite data sets 
TABLE 2. $\quad 850-300 \mathrm{mb}$ thickness (meters) comparisons.

\begin{tabular}{lccc}
\hline \hline Data & RMS & Bias & $S_{1}$ \\
\hline CRB & \multicolumn{3}{c}{ Verification data set } \\
DST & $31.77 \mathrm{~m}$ & $3.27 \mathrm{~m}$ & 41.63 \\
MWR & 31.76 & -11.97 & 41.37 \\
MAN & 31.25 & 2.49 & 40.09 \\
GCL & 23.45 & 4.89 & 30.09 \\
RR1 & 19.14 & 4.51 & 34.05 \\
RS1 & 14.02 & 2.33 & 23.33 \\
RR2 & 29.94 & 0.47 & 40.44 \\
RS2 & 16.89 & 3.47 & 22.78 \\
\hline
\end{tabular}

show a negative bias for all sets (except DST) at $850 \mathrm{mb}$, but nearly all positive values at 500 and $300 \mathrm{mb}$. This tendency indicates that the retrieved level temperatures at $850 \mathrm{mb}$ are too low, while at 500 and $300 \mathrm{mb}$ they are too high. This situation commonly occurs when some of the HIRS retrievals are contaminated by clouds.

To investigate this problem further, maps were prepared showing the distribution of the temperature differences between the CRB and GCL data sets. In this comparison, the differences were calculated at the station locations rather than at grid point. (Recall that the CRB and GCL observations share common locations.) Although not presented here, the maps showed that the largest temperature differences were in regions of cloudiness. The results of the comparisons are summarized in the histograms of Fig. 5, which show the frequency of occurrence of various temperature differences. The shaded portions of the bars indicate GCL soundings retrieved in regions of at least partial cloudiness. At $850 \mathrm{mb}$ the cloudy soundings are strongly skewed toward "too cold" differences, while at $500 \mathrm{mb}$ the cloudy soundings are distributed more normally, but with some slight tendency toward "too cold." At $300 \mathrm{mb}$ the distribution leans slightly toward "too warm." Although there are also contributions to the GCL-CRB differences from clear areas, the pattern in the histograms suggests that the retrievals in the cloudier regions provide a larger contribution to the bias values shown in Table 1. This occurs even though the soundings were selected manually with the intent of using a single field of view to reduce cloud contamination, and even though the $\mathrm{N}$-star (clear column) technique was used to lessen cloud contamination in regions of partial cloud cover.

Finally, it should be noted that some of the larger temperature differences between the radiosonde and the GCL data sets occurred in clear areas located between the Black and Caspian Seas. This is a region of pronounced surface variation-from large seas to the high Caucasus Mountains. The then-current retrieval methods often suffer in such locations, since the retrieval procedure assumes a surface at 1000 $\mathrm{mb}$ and the surface temperatures are replaced by extrapolated sea level temperatures.

\section{b. Thickness verifications}

The verifications obtained using the $850-300 \mathrm{mb}$ thickness are summarized in Table 2 . In calculating the thickness values from both satellite and radiosonde data sets, only
TABLE 3. $500 \mathrm{mb}$ height (meters) comparisons using CRB.

\begin{tabular}{|c|c|c|c|}
\hline \multicolumn{4}{|c|}{ a. Reduced radiosonde sets-only mandatory-level data } \\
\hline Data & RMS & Bias & $S_{\mathrm{t}}$ \\
\hline CRB & \multicolumn{3}{|c|}{ Verification data set } \\
\hline DST & $25.89 \mathrm{~m}$ & $-13.80 \mathrm{~m}$ & 37.74 \\
\hline MAN & 33.36 & -26.34 & 38.74 \\
\hline GCL & 27.07 & -22.74 & 28.41 \\
\hline RR1 & 28.00 & -21.57 & 33.28 \\
\hline RS1 & 26.41 & -23.67 & 22.40 \\
\hline RR2 & 29.83 & -19.13 & 38.99 \\
\hline RS2 & 24.83 & -22.13 & 22.52 \\
\hline \multicolumn{4}{|c|}{ b. Reduced radiosonde sets-mandatory- and significant-leve } \\
\hline Data & RMS & Bias & $S_{1}$ \\
\hline CRB & \multicolumn{3}{|c|}{ Verification data set } \\
\hline RR1 & 11.93 & 1.83 & 28.24 \\
\hline RS1 & 22.90 & -14.19 & 24.95 \\
\hline RR2 & 22.41 & -4.02 & 37.20 \\
\hline RS2 & 16.41 & -12.42 & 19.99 \\
\hline
\end{tabular}

mandatory-level data $(850,700,500,400$, and $300 \mathrm{mb})$ were used in the dry hypsometric equation. Since three of these levels were examined in the previous section, it is not surprising that the trends in Tables 1 and 2 are similar. Because satellite soundings are able to describe layer mean temperatures better than level temperatures, the results shown in Table 2 are somewhat better than those in Table 1. This is most evident in the $S_{1}$ scores, which are consistently between 4 and 10 points lower than in Table 1 . In the thickness calculations, the negative bias in the $850 \mathrm{mb}$ temperatures tends to be compensated for by the somewhat positive bias at $300 \mathrm{mb}$. As in the case of the level temperature comparisons, the use of the MWR set provides essentially no improvement over the DST data, and the HIRS MAN set offers only a negligible improvement. However, the HIRS GCL set provides substantial improvement, with the $S_{1}$ score decreasing by 10 points and the rms difference by about $8 \mathrm{~m}$ when compared with the MAN set. Again, the lowest $S_{1}$ scores are achieved when GCL soundings are combined with the reduced radiosonde networks to form the R1S and R2S sets.

\section{c. $500 \mathrm{mb}$ height verifications}

The CRB $500 \mathrm{mb}$ heights used in the verifications were the heights reported in the radiosonde transmissions. These

TABLE 4. $500 \mathrm{mb}$ height (meters) comparisons using CRM.

\begin{tabular}{lccc}
\hline \hline Data & RMS & Bias & $S_{1}$ \\
\hline CRB & \multicolumn{3}{c}{ Verification data set } \\
DST & $21.63 \mathrm{~m}$ & $9.56 \mathrm{~m}$ & 33.70 \\
MAN & 18.69 & -2.98 & 37.33 \\
GCL & 12.51 & 0.62 & 24.97 \\
RR1 & 12.82 & 1.79 & 28.28 \\
RS1 & 8.13 & -0.31 & 17.35 \\
RR2 & 23.86 & 4.23 & 35.35 \\
RS2 & 8.40 & 1.24 & 17.14 \\
\hline
\end{tabular}



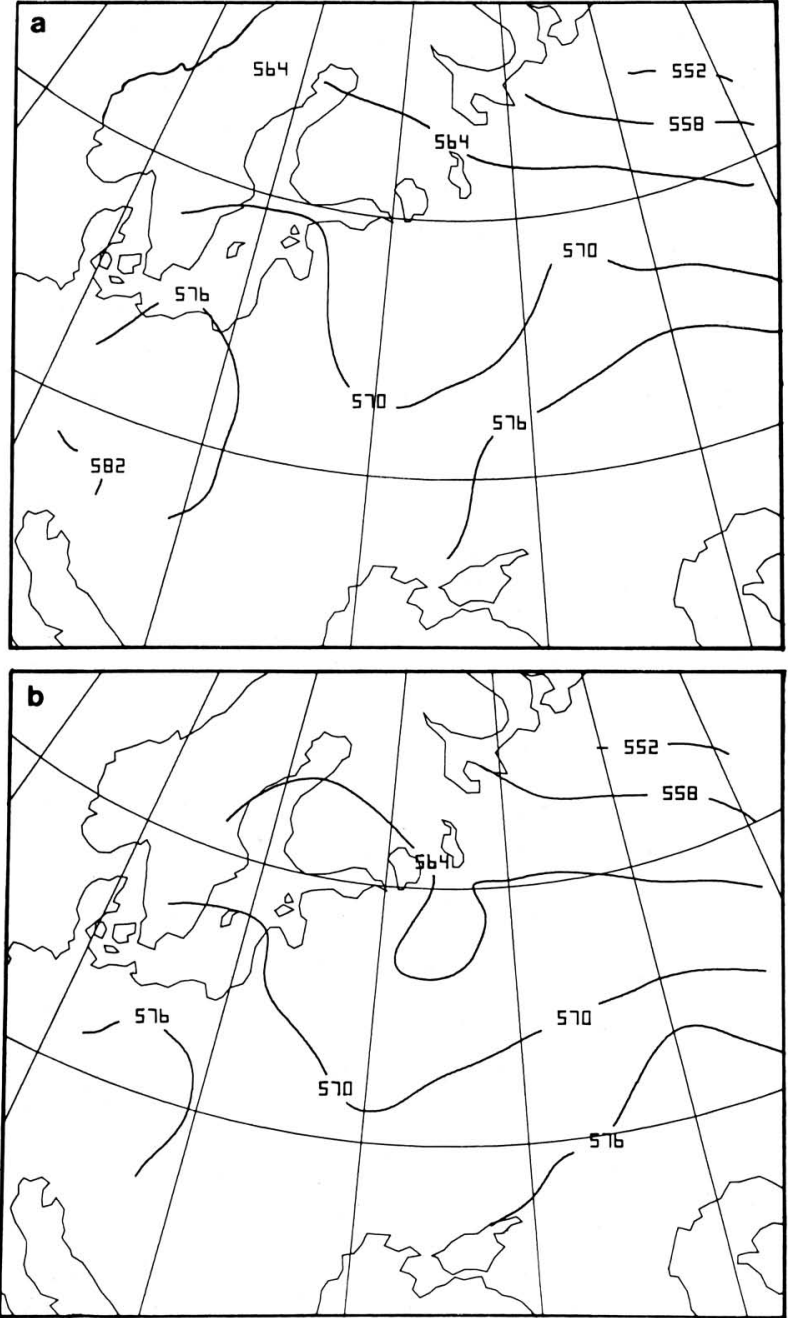

FIG. 6. $500 \mathrm{mb}$ height analyses for $0000 \mathrm{GMT}$ on 21 August 1975 based on radiosonde data only: a) heights obtained from CRB data, which include mandatory- and significant-level moist data; b) heights obtained from CRM data, which use only dry, mandatory data.

heights are calculated at radiosonde stations prior to transmission, using significant- and mandatory-level temperatures and moisture (virtual temperatures). The $500 \mathrm{mb}$ heights for the satellite and reduced radiosonde sets were achieved by using only mandatory-level data and the dry hypsometric equation to compute the $1000-500 \mathrm{mb}$ thickness. These thickness values then were added to the $1000 \mathrm{mb}$ heights obtained from the CRB data to obtain the $500 \mathrm{mb}$ heights. Thus, this $500 \mathrm{mb}$ height verification principally tests the ability of the satellite and reduced radiosonde data to describe the 1000-500 mb thickness.

Table 3a displays the $500 \mathrm{mb}$ height results. In this test the MWR set was not included. Perhaps the most striking feature of the table is the rather uniform scores in the rms and bias columns. The negative bias is very pronounced. Only the DST data have a relatively low negative bias. However, in the $S_{1}$ scores the GCL satellite data fare considerably better than the DST set, and when the GCL data are combined with RR 1 and RR2 sets to form RS1 and RS2, they produce a marked improvement in the $S_{1}$ scores.
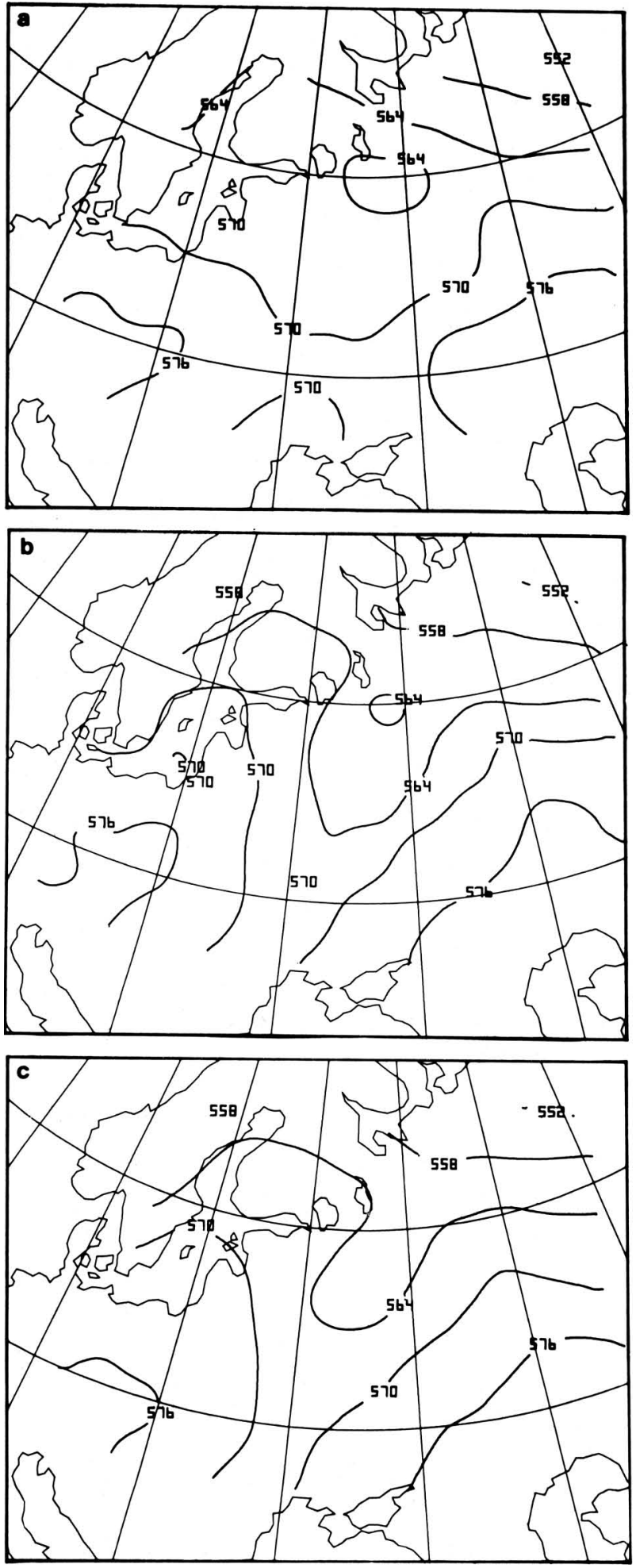

FIG. 7. $500 \mathrm{mb}$ height analyses based on Nimbus-6 satellite data for about 0000 GMT on 21 August 1975: a) DST data set, b) HIRS MAN data, c) HIRS GCL data.

Because of the large negative bias in the reduced radiosonde network data, a set of $500 \mathrm{mb}$ heights was prepared in which the significant-level radiosonde data were included in the RR 1 and RR2 height calculations. The results in Table $3 \mathrm{~b}$ show large improvements in the bias and, consequently, also 

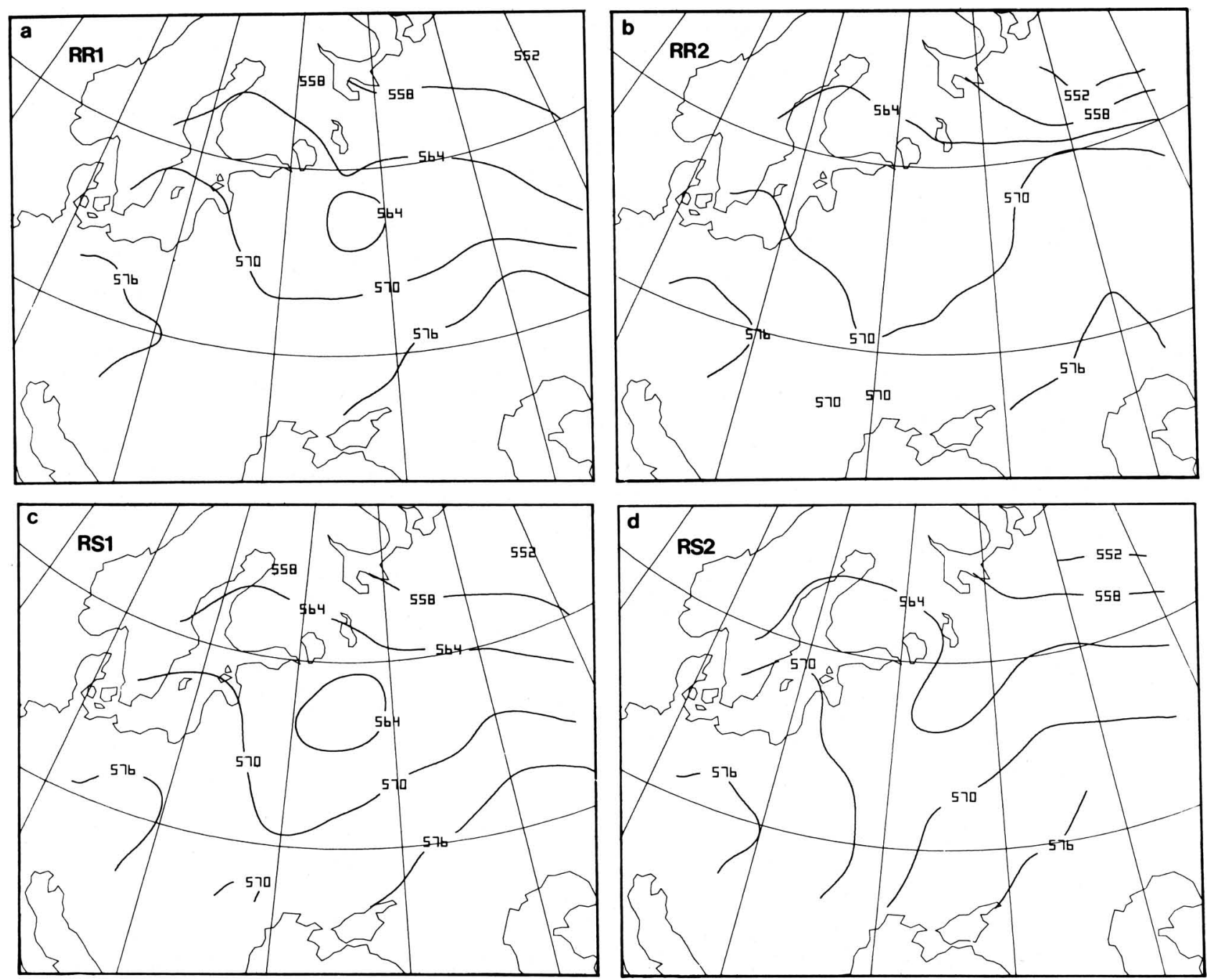

FIG. 8. $500 \mathrm{mb}$ height analyses obtained from: a) RR1 network data, b) RR2 network data, c) a combination of RR1 and GCL data to form the RS1 data set,d) a combination of RR2 and GCL data to form the RS2 data set. See text.

in the rms. The RR 1 bias improves from $-21.57 \mathrm{~m}$ to +1.83 $\mathrm{m}$, and the less-uniformly spaced RR2 network from -19.13 $\mathrm{m}$ to $-4.02 \mathrm{~m}$. When the satellite GCL data were included at the deleted radiosonde stations to form RS1 and RS2, the bias became significantly negative again, but improvements were made in the $S_{1}$ scores. This reflects a "cold" bias in the satellite data, which was caused by the presence of nocturnal surface temperature inversions. Inversions of $5^{\circ} \mathrm{C}$ within 30 $\mathrm{mb}$ below the $900 \mathrm{mb}$ level in the radiosonde soundings were common, and at one station an $11^{\circ} \mathrm{C}$ inversion was present. When only mandatory-level radiosonde data are used, this warm layer between 1000 and $850 \mathrm{mb}$ is lost. Similarly, satellite soundings, with their poor vertical resolution, are unable to capture this warm layer.

One additional test was conducted. Here, the $500 \mathrm{mb}$ height verification data was rederived using all 96 radiosonde stations, but employing only their mandatory-level temperature data. Moisture was ignored. ${ }^{3}$ This verification data set will be called the CRM set (complete set of radiosonde sta-

\footnotetext{
${ }^{3} \mathrm{~A}$ data set based on mandatory, moist (virtual temperature) data also was obtained, but it was nearly identical to the dry case.
}

tions, but only mandatory-level data). The comparison between the CRB and CRM sets produced large rms $(24.87 \mathrm{~m})$ and bias $(-23.76 \mathrm{~m})$ values. The "cold" bias in the CRM set is striking; it explains more than $90 \%$ of the rms value. However, the $S_{1}$ score (16.35) between the two sets is very good.

The results achieved using CRM for verification are shown in Table 4. There is a large improvement in the rms and bias values over those shown in Table 3. It is now the DST set that has the largest rms and bias values. The $S_{1}$ scores are somewhat better in Table 4, but the major impact is in the bias and, consequently, in the rms. It is noteworthy that the addition of GCL satellite soundings to the RR1 and RR2 networks to form the RS1 and RS2 sets gives excellent results. The bias and rms in the RS1 and RS2 sets are reduced greatly, and the $S_{1}$ scores of 17.35 and 17.14 are essentially as good as that calculated between the two complete radiosonde networks (16.35).

Figures 6, 7, and 8 show the various $500 \mathrm{mb}$ analyses over eastern Europe. The two complete radiosonde network analyses are displayed in Fig. 6. They are quite similar except for a slightly deeper trough in the mandatory-level data analysis. 
Figure 7 shows the DST, MAN, and GCL $500 \mathrm{mb}$ analyses. Note the noisier contours in the MAN (Fig. 7b) analysis compared to those in the GCL analysis (Fig. 7c). This characteristic is similar to that seen in the $850 \mathrm{mb}$ temperature analyses (Fig. 4). Also note that the GCL pattern (Fig. 7c) more closely resembles the CRM pattern (Fig. 6b) than does the DST pattern (7a).

Finally, Figs. $8 \mathrm{a}$ and $8 \mathrm{~b}$ display the results achieved from the RR1 and RR2 data with only mandatory-level data. Figures $8 \mathrm{c}$ and $8 \mathrm{~d}$ incorporate HIRS GCL soundings at the missing radiosonde locations. These figures support the findings of Table 4. The addition of well-screened satellite soundings to an incomplete network of mandatory-level radiosonde data can produce improved analyses. Thus, satellite soundings of the quality of the GCL HIRS data appear to be compatible with mandatory-level radiosonde data.

\section{Conclusions}

The results of this study indicate that the careful editing of satellite retrievals can produce a set of soundings comparable to mandatory-level radiosonde data. The individual soundings (single spots) MAN set obtained here offered little improvement over the DST data. Single soundings co-located with 93 radiosonde locations provided some improvement over the MAN set; however, it was the averages of about five individual soundings interpolated to radiosonde locations (the GCL set) that produced soundings that were definitely superior to the DST data. While there is certainly nothing unique about choosing five soundings for the averaging, it seems clear that single soundings are likely to produce a somewhat noisy field.

Even though special editing procedures were employed to obtain the MAN and GCL sets from the Nimbus-6 HIRS data, it is apparent that there was some cloud contamination of the infrared data. This is illustrated best in Fig. 5, which shows a tendency for a slightly "cold" bias at $850 \mathrm{mb}$ and a "warm" bias at $300 \mathrm{mb}$. However, the relatively good performance of the GCL data set indicates that the problem was not at all severe.

The use of reduced radiosonde networks (RR1 and RR2) made it possible to examine the compatibility of satellite soundings with conventional radiosonde observations. Table $3 b$ illustrates that even though horizontal gradients are defined better with the inclusion of satellite soundings (improved $S_{1}$ scores), the lack of vertical resolution in satellite soundings produces rather large rms and bias values.

Significant nocturnal surface temperature inversions were present at the time of the observations, two to three hours past local midnight. They had a major impact, as is evident in Tables 3 and 4 . Since satellite soundings do not have sufficient vertical resolution to capture these inversions, the user of these data should be especially cautious with nighttime soundings over land areas. The problem is made more acute if the satellite data are combined with radiosonde data consisting of both mandatory-and significant-level information. However, over ocean areas, where nocturnal inversions are uncommon, this problem is alleviated somewhat. Therefore, the best opportunity for satellite soundings to fill in gaps in numerical model input exists over these areas. Nevertheless, further investigation is warranted into how nighttime retrievals over land can be improved.

Acknowledgments. We especially thank Dr. Christopher Hayden for his assistance in both establishing the McIDAS retrieval procedure and commenting on the manuscript. Dr. Thomas Koehler provided helpful comments during various stages of the work. Mary Hansen Bleisner, John Derber, and John Buck assisted in the early portion of the work and Brian Jarvis and Kathi Marvin in the latter stage. Finally, it should be noted that brisk comments by reviewer Dr. Norman Phillips strengthened the final manuscript. The research was supported by NOAA Grant numbers 04-4-158-2 and NA 79AA-H-00011.

\section{References}

Ghil, M., M. Halem, and R. Atlas, 1979: Time-continuous assimilation of remote-sounding data and its effect on weather forecasting. Mon. Wea. Rev., 107, 140-171.

Greaves, J. R., G. DiMego, W. L. Smith, and V. E. Suomi, 1979: A special effort to provide improved sounding and cloud motion wind data for FGGE. Bull. Am. Meteorol. Soc., 60, 124-127.

Horn, L. H., R. A. Petersen, and T. M. Whittaker, 1976: Intercomparisons of data derived from Nimbus-5 temperature profiles, rawinsonde observations, and initialized LFM model fields. Mon. Wea. Rev., 104, 1362-1371.

Kelly, G. A. M., G. A. Mills, and W. L. Smith, 1978: Impact of Nimbus- 6 temperature soundings on Australian region forecasts. Bull. Am. Meteorol. Soc., 59, 393-405.

NASA, 1975: Nimbus-6 User's Guide. Goddard Space Flight Center, Greenbelt, Md.

Petersen, R. A., and L. H. Horn, 1977: An evaluation of $500 \mathrm{mb}$ height and geostrophic wind fields derived from Nimbus-6 soundings. Bull. Am. Meteorol. Soc., 58, 1195-1201.

Phillips, N., L. McMillin, A. Gruber, and D. Wark, 1979: An evaluation of early operational temperature soundings from TIROS-N. Bull. Am. Meteorol. Soc., 60, 1188-1197.

Smith, W. L., 1968: An improved method for calculating tropospheric temperature and moisture from satellite radiometer measurements. Mon. Wea. Rev., 96, 387-396.

— covariance matrices for interpreting satellite sounding radiometer observations. J. Atmos. Sci., 33, 1127-1140.

- C. M. Hayden, H. M. Woolf, H. B. Howell, and F. W. Nagle, 1979: Satellite sounding applications to mesoscale meteorology. Remote Sounding of the Atmosphere from Space, Pergamon Press, Oxford, England, p. 33-47.

Tracton, M. S., A. J. Desmarais, R. J. van Haaren, and R. D. McPherson, 1980: The impact of satellite soundings upon the National Meteorological Center's analysis and forecast systemThe Data System's Test results. Mon. Wea. Rev., 108, 543-586.

Whittaker, T. M., 1976: A simplified grid interpolation scheme for use in atmospheric budget studies. M. S. thesis, Dept. of Meteorology, University of Wisconsin, Madison, Wis., $42 \mathrm{pp}$.

Corrigendum-In GARP Topics No. 67, which appeared in the June 81 issue of the BULLETIN, an incorrect logo for The Alpine Experiment was printed. The correct logo is printed on p. 1370 of this issue. 